\title{
Correlation between Blood Flow Signal of Color Flow Imaging and Nottingham Prognostic Index in Patients with Breast Carcinoma
}

\author{
Zhi-Yong Shen ${ }^{a, b} \quad$ Bing $\mathrm{Hu}^{\mathrm{a}}$ Ming-Feng Wu $\mathrm{Wu}^{\mathrm{b}}$

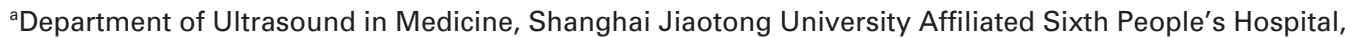 \\ Shanghai Institute of Ultrasound in Medicine, Shanghai,

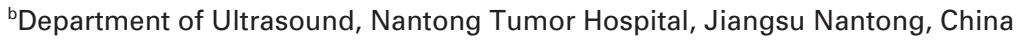

\section{Keywords}

Ductal carcinoma - Ultrasonography, color Doppler .

Breast neoplasm - Nottingham Prognostic Index

\section{Summary}

Background: The purpose of this study was to investigate the relationship between blood supply detected by Doppler ultrasound and the Nottingham Prognostic Index (NPI) in breast cancer patients. Patients and Methods: 137 patients with breast carcinoma, who had undergone color Doppler flow imaging (CDFI) and surgery, were involved in this retrospective study. CDFI was divided into 4 levels: absent (grade 0), minimal (grade 1), moderate (grade 2), and marked (grade 3). NPI was calculated as: $\mathrm{NPI}=0.2 \times$ tumor size $(\mathrm{cm})+$ grade $(\mathrm{I}-\mathrm{III})+$ lymph node score (1-3). All patients were followed until the final observation (July 2010), or until the time of death. The survival state of the patients was divided into 3 categories: healthy survival, metastasis, and death. Results: Blood signal grades were positively correlated with NPI (Spearman $r=0.55926, p<0.0001$ ) and survival state $\left(\chi^{2}=9.0248, p<0.01\right)$. Patients with abundant blood flow signal (grade $2-3$ ) had a significantly shorter overall survival than did those with limited blood flow signal (grade $0-1)\left(\chi^{2}=5.0384, p=0.0248\right)$. Conclusion: Flow signal measured by Doppler ultrasound may be useful as a prognostic indicator for patients with breast carcinoma.

\section{Schlüsselwörter \\ Duktales Karzinom - Ultrasonographie, Farbdoppler . Mammatumor - Nottingham Prognostic Index}

\section{Zusammenfassung}

Hintergrund: Ziel dieser Studie war es, die Beziehung zwischen der mittels Doppler-Ultraschall detektierten Blutversorgung und dem Nottingham Prognostic Index (NPI) bei Brustkrebspatientinnen zu untersuchen. Patienten und Methoden: 137 chirurgisch behandelte Brustkrebspatientinnen, bei denen eine Farbdoppler-Sonographie zur Messung des Blutflusses (color Doppler flow imaging, CDFI) durchgeführt worden war, wurden in diese retrospektive Studie aufgenommen. CDFI wurde in 4 Grade unterteilt: abwesend (Grad 0), minimal (Grad 1), moderat (Grad 2) und ausgeprägt (Grad 3). Der NPI wurde nach folgender Formel berechnet: NPI $=0,2 \times$ Tumorgröße $(\mathrm{cm})+$ Grad (I-III) + Lymphknoten-Score (1-3). Alle Patientinnen wurden bis zum Studienende (Juli 2010) bzw. bis zum Zeitpunkt des Todes nachverfolgt. Der Überlebensstatus der Patientinnen wurde in 3 Kategorien eingeteilt: gesundes Überleben, Metastasen und Tod. Ergebnisse: Der CDFI-Grad war positiv mit dem NPI (Spearman $r=0,55926, p<0,0001$ ) und dem Überlebensstatus $\left(\chi^{2}=9,0248, p<0,01\right)$ korreliert. Patientinnen mit einem starken Blutfluss-Signal (Grad 2-3) hatten ein signifikant kürzeres Gesamtüberleben als Patientinnen mit einem geringen Blutfluss-Signal (Grad 0-1) $\left(\chi^{2}=5,0384, p=0,0248\right)$. Schlussfolgerung: Die Messung des Blutfluss-Signals mit Doppler-Ultraschall könnte ein nützlicher Prognosewert bei Brustkrebspatientinnen sein.

\section{KARGER}

Fax +497614520714

Information@Karger.de

www.karger.com
(C) 2012 S. Karger GmbH, Freiburg

$1661-3791 / 12 / 0072-0126 \$ 38.00 / 0$

Accessible online at:

www.karger.com/brc
Bing Hu, M.D

Department of Ultrasound in Medicine

Shanghai Institute of Ultrasound in Medicine

Shanghai Jiaotong University affiliated Sixth People's Hospital

No. 600, Yishan Road, Shanghai200233, P.R. China

Hub1523@hotmail.com 


\section{Introduction}

Tumor growth and the formation of metastases require the development of new blood vessels, a process known as angiogenesis. Breast cancer tends to produce angiogenic factors that influence blood vessel growth [1]. Neovascularization can be found inside the tumor and in the peritumoral tissue. Blood vessels in tumors are known to be highly disorganized, tortuous, and dilated, with uneven diameters and excessive branching [2]. Color Doppler flow imaging (CDFI) allows to visualize tumor vascularity, and it is an established technique for evaluation of angiogenesis [3]. CDFI can show neovascularization of carcinomas with an irregular vascular pattern, artery-venous shunts, and a lack of autoregulation in contrast to normal vessels in the breast parenchyma. Many researchers have studied the relationship between the vascularization of breast tissue detected by Doppler ultrasound (US) and patient prognosis [4-7]. A positive association has been found between metastasis and higher flow velocity in breast tumors [5-7]. Sonographic measurement of tumor vascularity also correlates well with microvessel density, confirmed by postoperative immunohistochemical analysis, which was shown to be a prognostic factor of breast cancer [5]. High vascular grades have been associated with shorter disease-free survival [8]. The Nottingham Prognostic Index (NPI) was established by Haybittle et al. [9] in 1982 and is still one of the most important biological predictors for breast cancer today [10]. A few papers have researched the relationship between CDFI and NPI [11]. This study will explore the relationship between CDFI and NPI, in order to roughly judge and predict the prognosis of patients suffering from breast cancer.

\section{Materials and Methods}

\section{Clinical Data}

We retrospectively reviewed the records of 137 consecutive breast carcinoma patients hospitalized in Nantong Tumor Hospital between 2003 and 2007. Examination of the patients was performed with the approval of the ethics committee of our hospital. Written consent for this research was obtained from the patients or their relatives. The records, files, images, and follow-up data were all obtained with the approval or informed consent of the patients or their relatives. The patients ranged in age from 28 to 81 years (mean 56 years), and the breast carcinomas ranged in diameter from 0.8 to $5.5 \mathrm{~cm}$ (mean $2.7 \mathrm{~cm}$ ). There were 124 palpable cancers in this study. 123 patients underwent modified radical mastectomy, with the other 14 cases undergoing radical operation.

\section{Nottingham Prognostic Index}

Pathologic results were reviewed to evaluate tumor size, lymph node status, and histological grade. The NPI was calculated using the equation NPI $=0.2 \times$ tumor size $(\mathrm{cm})+$ grade $(\mathrm{I}-\mathrm{III})+$ lymph node score $(1-3)$ [12]. NPI are typically stratified into 3 major groups: NPI $<3.4$ (good prognosis), NPI 3.4-5.4 (moderate prognosis), and NPI > 5.4 (poor prognosis) [13].

\section{CDFI Studies}

US diagnosis was performed by 2 operators, each having more than 10 years of experience with CDFI examinations. All examinations were recorded digitally on video. Color flow images of the breast masses were obtained using an HDI 5000 scanner (Philips Medical Systems, Bothell, WA, USA). For this study, sensitivity of the instrument was set at low velocity in order to display low blood flow signal. Only the intratumoral blood signal was evaluated. The degree of blood flow signal within the breast carcinomas was subjectively classified into 1 of 4 levels, according to Adler's method [14]: absent (grade 0), minimal (grade 1), moderate (grade 2 ), or marked (grade 3 ).

\section{Statistical Analysis}

The correlation between blood signal grade and NPI was analyzed using the Spearman's rank correlation coefficient (Spearman's r). Survival state of the patients was divided into 3 categories: healthy, metastasis, and deceased. Survival outcomes were obtained using telephone calls and letters sent out from our hospital. At the time of the final observation (July 2010), all patients had been followed for a minimum of 31 months (median 62 months, range 31-91 months). The relationship between CDFI grade and survival state was determined using the $\chi^{2}$ test. Patients were divided into 2 groups: Group 1 comprised patients with lower blood flow signal (grades $0-1$ ), and Group 2 comprised patients with higher blood flow signal (grades 2-3). Survival time was calculated based on information gathered during follow-up, and related to the date of surgery and the date of death. If a patient was still alive at the end of July 2010, survival time was calculated using a right censoring survival model. The survival curves were calculated using the Kaplan-Meier method and were analyzed using the log-rank test. All statistical analyses were performed with SAS 8.5 software (StatView; SAS Institute Inc., Cary, NC, USA). A p value of less than 0.05 was considered statistically significant.

\section{Results}

\section{Pathological Findings after Surgery}

In the following, a summary of the pathological findings for tumor size, histological grade, and degree of metastasis is given. There were 2 cases with tumor size $<1 \mathrm{~cm}, 35$ cases measuring 1-2 cm, 53 cases measuring $2-3 \mathrm{~cm}, 34$ cases measuring 3-4 cm, and 13 cases $>4 \mathrm{~cm}$, including the largest one with a nodule size of $5.5 \mathrm{~cm}$. Histological grading of the tumors yielded 41 cases with grade 1, 47 cases with grade 2, and 49 cases with grade 3 . Pathological findings for lymph node metastasis were as follows: 45 patients were negative for lymph node metastasis; 15 patients had 1 lymph node metastasis; 13 patients had 2 metastases; 24 cases had 3 metastases; 16 cases had 4 metastases; and 24 cases had more than 5 lymph node metastases, including 1 case with up to 13 involved lymph nodes.

\section{CDFI Results}

US demonstrated that the level of angiogenesis varied with different NPI scores (figs. 1-2). The CDFI grade was positively correlated with NPI (Spearman's $r=0.55926$, $\mathrm{p}<0.0001)$. Table 1 shows the relationship between flow signal grade and NPI score. 


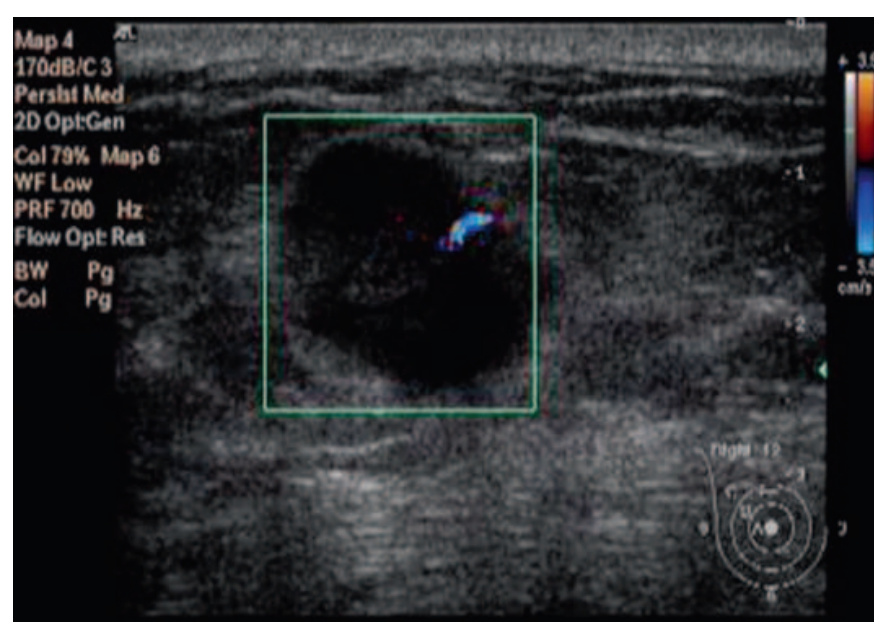

Fig. 1. Ultrasonic image of a breast mass with CDFI flow signal grade 1 and a diameter of $17 \mathrm{~mm}$. Pathology indicated the mass had a histologic grade of 2 and was negative for axillary node metastasis with an NPI of 3.3 .

Table 1. Distribution of NPI scores for each flow signal grade shows a relationship between blood flow level and NPI $(r=0.55926, p<0.0001)$

\begin{tabular}{llll}
\hline CDFI grade & NPI & & \\
\cline { 2 - 4 } & $<3.4$ & $3.4-5.4$ & $>5.4$ \\
\hline 0 & 18 & 15 & 2 \\
1 & 14 & 16 & 4 \\
2 & 5 & 13 & 11 \\
3 & 3 & 8 & 28 \\
\hline
\end{tabular}

CDFI $=$ Color Doppler flow imaging,

NPI $=$ Nottingham Prognostic Index.

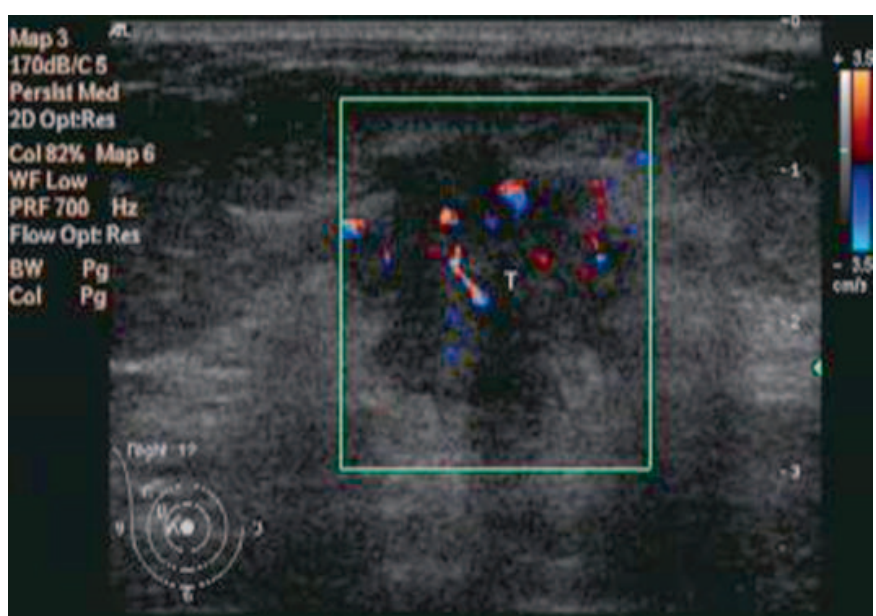

Fig. 2. Ultrasonic image of a breast mass with CDFI flow signal grade 3 and a diameter of $21 \mathrm{~mm}$. Pathology indicated the mass had a histologic grade of 3 and 6 metastastic axillary lymph nodes with an NPI of 6.4 .

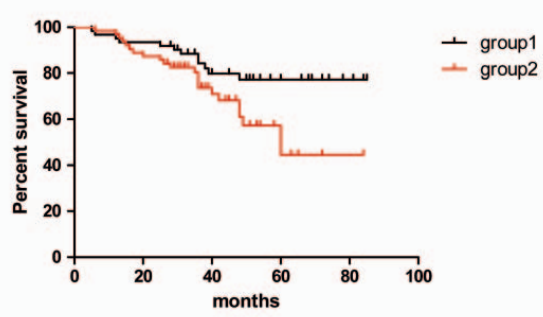

Fig. 3. Survival distribution of the patients. Group 1 (black curve) was composed of patients with tumor CDFI grades $0-1$, while group 2 (red curve) was composed of patients with tumor CDFI grades 2-3. Patients of group 2 had a significantly shorter overall survival than did those of group 1 (log-rank test, $\left.\chi^{2}=5.0384, \mathrm{p}=0.0248\right)$.
Table 2. Patient follow-up revealed a number of metastases to various locations; table lists the number of cases to each metastatic site, within each CDFI classification

\begin{tabular}{lllllll}
\hline CDFI grade & \multicolumn{2}{l}{ Metastatic site } & & & \\
\cline { 2 - 7 } & supraclavicular & lung & skeleton & chest wall & liver & lumbar \\
\hline 0 & & 2 & 1 & 1 & & 2 \\
1 & 1 & 1 & & 3 & 1 & \\
2 & 3 & & & 1 & \\
3 & \multicolumn{7}{l}{ CDFI = Color Doppler flow imaging. } \\
\hline
\end{tabular}

Table 3. Distribution of survival state according to CDFI grade; significanct correlation between blood flow signal revealed by CDFI and survival state $\left(\chi^{2}=9.0248, p=0.0027\right)$

\begin{tabular}{llll}
\hline \multirow{2}{*}{ CDFI grade } & \multicolumn{3}{l}{ Survival state } \\
\cline { 2 - 4 } & healthy & metastasis & deceased \\
\hline 0 & 26 & 2 & 7 \\
1 & 25 & 4 & 5 \\
2 & 20 & 5 & 4 \\
3 & 16 & 5 & 18 \\
\hline \multicolumn{2}{l}{ CDFI = Color Doppler flow imaging. }
\end{tabular}

CDFI $=$ Color Doppler flow imaging.

\section{Follow-Up Results}

During the follow-up period, 103 patients survived, among which 87 patients had disease-free survival (63.5\%); disease spread occurred in 16 women (11.68\%). The mortality rate was $24.82 \%$ (34 patients). The metastatic sites for patients with disease spread are shown in table 2. Table 3 shows that there was a trend towards significance for correlation between blood flow signal and survival state $\left(\chi^{2}=9.0248, \mathrm{p}=0.0027\right)$. Postoperative survival rates for all patients are shown in figure 3. Patients with higher signal had a significantly shorter overall survival than those with low blood signal $\left(\chi^{2}=5.0384\right.$, $\mathrm{p}=0.0248)$. 


\section{Discussion}

The vascular assessment of CDFI aims to provide information on the degree of neovascularization which correlates with the biological behavior of the tumor. The vascularization of a breast lesion can be investigated using color-coded and frequency-based Doppler analysis $[15,16]$. Quantification of intratumoral vascularity involves a number of measures, including peak systolic velocity $\left(\mathrm{V}_{\max }\right)$, minimum velocity $\left(\mathrm{V}_{\min }\right)$, and resistance index (RI). While these variables have their advantages, measurement of the number of vessels seems to be more ideal than that of $V_{\max }$ with Doppler US [17-19]. The evaluation of blood flow signal grade, however, is relatively simple and has shown good reproducibility between different ultrasonologists. Therefore, in this paper, we assess tumor vascularity using a sonography-based blood flow grading system [14].

Regarding the relationship between ultrasonic blood signal and NPI, rank correlation analysis indicated a statistically significant correlation between NPI and color Doppler measures of tumor vascularity $(r=0.55926, p<0.0001)$, suggesting that with the increase in blood flow, NPI also increased (figs. 1-2). NPI is based on tumor size, histologic grade, and lymph node status. CDFI has a close relationship with each of these factors. First, tumor growth depends on blood supply; the larger the tumor, the more blood supply it needs. Chao et al. [4] found that tumor size was associated with the number of vessels detected by color Doppler US. This is similar to the findings of Cosgrove et al. [20] who demonstrated that the number of vessels in malignant tumors displayed on Doppler US was related to tumor size. Second, different grades of invasive ductal carcinomas are associated with different blood flow, and vascular index was higher in tumors with higher histologic grade [21, 22]. Third, among malignant cases, tumor vascularity has been correlated with lymph node involvement [7, 23]. Chao et al. [4] reported that, of 20 patients showing no tumor vascularity on Doppler US, $12(60 \%)$ had no lymph node metastases. Of 348 patients with tumor vascularity, 160 (46\%) had no lymph node metastases. Patients with breast cancer, in whom vessels were not revealed by sonography, were unlikely to have lymph node involvement or lymphatic vascular invasion [24, 25]. In short, the blood flow signal is related to 3 components: tumor size, tissue differentiation, and lymph node metastasis. Semi-quantitative evaluation of the results indicates that the degree of blood flow significantly correlates with NPI. Individuals with higher flow signal are linked with increased NPI and poor prognosis.

To investigate the relationship between degree of blood flow and survival, all patients were followed up for a median time of 62 months. There was a correlation between blood flow signal grading and survival status, with statistical analysis showing $\chi^{2}=9.0248, \mathrm{p}=0.0027$ (table 3). Patients with low flow signals in the breast neoplasm had better survival outcomes, while patients with high blood flow had poorer out- comes. The overall survival rate of patients with $0-1$ grade blood signal was compared to that of patients with 2-3 grade signal. An association between vascular grade and overall survival was studied using Kaplan-Meier survival curves, and a significant correlation was revealed between high vascularity and increased probability of death. Patients with higher blood signals had shorter survival periods (fig. 3). Therefore, angiogenesis, which can be detected by color-coded sonography, is an important prognostic indicator. This finding is consistent with other reports [7, 26]. Anti-angiogenic therapies, such as bevacizumab (an adjuvant chemotherapy for breast cancer), have been shown to prolong survival [27]. Angiogenesis affects tumor growth and metastasis, thus determining the patient's prognosis. CDFI therefore may provide important prognostic information for breast cancer patients.

Compared with some other studies [7], the breast tumors included in our study were relatively large. There are 2 reasons for this: First, early breast cancer has no obvious symptoms such as pain, and this absence of symptoms can make patients negligent in seeking medical treatment. Second, due to economic conditions and poor sense of self-care, many patients in the rural areas came to the outpatient clinic only when the tumor was obviously palpable. Therefore, one disadvantage of this study is that it did not include early breast cancer patients. However, tumor vascularization detected by Doppler US appears to be also an independent predictor of overall survival in women with early breast cancer [7], and our results may be a useful complement to prior research.

There are limitations in our research. Power Doppler US and 3-dimensional (3D) US can provide better visualization of vascular morphology than does color Doppler. However, 7 years ago, 3D and Power Doppler US were not routinely used. At our institute, only a few complicated breast lumps have been evaluated using Power Doppler, 3D, and contrast US. In the future, we will strengthen our efforts to use these up-to-date imaging methods to study the relationship between vascularity and prognosis.

\section{Conclusion}

Our initial studies showed that vascularization detected by CDFI is associated with NPI in breast cancer. Follow-up results also showed that the degree of blood flow correlated with the survival state of the patients. The more abundant the blood supply, the worse the prognosis. Blood flow in breast lesions reflects the nature of tumor biology, and blood flow detection by color Doppler US may provide a simple way to predict the prognosis of patients. However, further studies should be performed to properly validate the real prognostic value of intratumoral blood signal before this method can be considered for routine clinical practice in selecting those patients with high-risk breast cancer, who may benefit from active therapy. 


\section{Acknowledgements}

We sincerely thank Guo-Ming Xie for providing some important documents and good suggestions.

\section{Disclosure Statement}

The authors declare that they have no competing interests.

\section{References}

1 Khosravi Shahi P, Soria Lovelle A, Pérez Manga G: Tumoral angiogenesis and breast cancer. Clin Transl Oncol 2009;11:138-142.

2 Lee SW, Choi HY, Baek SY, Lim SM: Role of color and power Doppler imaging in differentiating between malignant and benign solid breast masses. J Clin Ultrasound 2002;30:459-464.

3 Sehgal CM, Meinstein SP, Arger PH ,Conant EF: A review of breast ultrasound. J Mammary Gland Biol Neoplasia 2006;11:113-123.

4 Chao TC, Luo YF, Chen SC, Chen MF: Color Doppler ultrasound in breast carcinomas: relationship with hormone receptors, DNA ploidy, S-phase fraction, and histopathology. Ultrasound Med Biol 2001;27:351-355.

5 Yang WT, Tse GM, Lam PK, Metreweli C, Chang J: Correlation between color power Doppler sonographic measurement of breast tumor vasculature and immunohistochemical analysis of microvessel density for the quantitation of angiogenesis. J Ultrasound Med 2002;21:1227-1235.

6 Exacoustos C, Zupi E, Cangi B, Chiaretti M, Arduini D, Romanini C: Endometrial evaluation in postmenopausal breast cancer patients receiving tamoxifen: an ultrasound, color flow Doppler, hysteroscopic and histological study. Ultrasound Obstet Gynecol 1995;6:435-442.

7 Watermann D, Madjar H, Sauerbrei W, Hirt V, Prömpeler H, Stickeler E: Assessment of breast cancer vascularisation by Doppler ultrasound as a prognostic factor of survival. Oncol Rep 2004; 11:905-910.

8 Dhakal HP, Naume B, Synnestvedt M, Borgen E, Kaaresen R, Schlichting E, et al.: Vascularization in primary breast carcinomas: its prognostic significance and relationship with tumor cell dissemination. Clin Cancer Res 2008;14:2341-2350.

$\checkmark 9$ Haybittle JL, Blarney RW, Elston CW, Johnson J, Doyle PJ, Campbell FC, et al.: A prognostic index in primary breast cancer. Br J Cancer 1982,45:361366.
10 Megha T, Neri A, Malagnino V, Caruso S, Onorati M, Roviello F, et al.: Traditional and new prognosticators in breast cancer: Nottingham index, Mib-1 and estrogen receptor signaling remain the best predictors of relapse and survival in a series of 289 cases. Cancer Biol Ther 2010;9:266273.

11 Osanai T, Wakita T, Gomi N, Takenaka S, Kakimoto M, Sugihara K: Correlation among intratumoral blood flow in breast cancer, clinicopathological findings and Nottingham Prognostic Index. Jpn J Clin Oncol 2003;33:14-16.

12 Lee AH, Ellis IO: The Nottingham prognostic index for invasive carcinoma of the breast. Pathol Oncol Res 2008;14:113-115.

13 Kollias J, Elston CW, Ellis IO, Robertson JF, Blamey RW: Early-onset breast cancer - histopathological and prognostic considerations. Br J Cancer 1997;75:1318-1323.

14 Adler DD, Carson PL, Rubin JM, Quinn-Reid D: Doppler ultrasound color flow imaging in the study of breast cancer: preliminary findings. Ultrasound Med Biol 1990;16:553-559.

15 Del Cura JL, Elizagaray E, Zabala R, Legorburu A, Grande D: The use of unenhanced Doppler sonography in the evaluation of solid breast lesions. AJR 2005;184:1788-1794.

16 Sehgal CM, Arger PH, Rowling SE, Conant EF, Reynolds C, Patton JA: Quantitative vascularity of breast masses by Doppler imaging: regional variations and diagnostic implications. J Ultrasound Med 2000;19:427-440.

17 Kim SW, Park SS, Ahn SJ, Chung KW, Moon WK, Im JG, Yeo JS, Chung JK, Noh DY: Identification of angiogenesis in primary breast carcinoma according to the image analysis. Breast Cancer Res Treat 2002;74:121-129.

18 Madjar H, Sauerbrei W, Prömpeler HJ, Wolfarth R, Gufler H: Color doppler and duplex flow analysis for classification of breast lesions. Gynecol Oncol 1997;64:392-403.
19 Sauerbrei W, Madjar H, Prömpeler HJ: Differentiation of benign and malignant breast tumors by logistic regression and a classification tree using Doppler flow signals. Methods Inf Med 1998;37:226-234.

20 Cosgrove DO, Kedar RP, Bamber JC, et al.: Breast diseases: color Doppler US in differential diagnosis. Radiology 1993;189:99-104.

21 Gasparini G, Weidner N, Bevilacqua P, Maluta S, Dalla Palma P, Caffo O, et al.: Tumor microvessel density, p53 expression, tumor size, and peritumoral lymphatic vessel invasion are relevant prognostic markers in node-negative breast carcinoma. J Clin Oncol 1994;12:454-466.

22 Linderholm B, Tavelin B, Grankvist K, Henriksson R: Vascular endothelial growth factor is of high prognostic value in node-negative breast carcinoma. J Clin Oncol 1998;16:3121-3128.

23 Kwak JY, Kim EK, Kim MJ, Choi SH, Son E, Oh KK: Power Doppler sonography: evaluation of solid breast lesions and correlation with lymph node metastasis. Clin Imaging 2008;32:167-171.

24 Kubek KA, Chan L, Frazier TG: Color Doppler flow as an indicator of nodal metastasis in solid breast masses. J Ultrasound Med 1996;15:835-841.

25 Mehta TS, Raza S: Power Doppler sonography of breast cancer: does vascularity correlate with node status or lymphatic vascular invasion? AJR 1999;173:303-307.

26 Toi M, Kashitani J, Tominaga T: Tumor angiogenesis is an independent prognostic indicator in primary breast carcinoma. Int $\mathrm{J}$ Cancer 1993;55:371-374.

27 Bahri S, Chen JH, Mehta RS, Carpenter PM Nie K, Kwon SY, et al.: Residual breast cancerdiagnosed by MRI in patients receiving neoadjuvant chemotherapy with and without bevacizumab. Ann Surg Oncol 2009;16:1619-1628. 